\title{
Analysis of Nitrogen Dioxide in Environment
}

\author{
Jun Wang1*, Wei Zhang ${ }^{2}$, Rui Cao ${ }^{3}$, Xiangyu You', Hong Lai ${ }^{4}$ \\ ${ }^{1}$ Department of Pharmacy, Food and Pharmaceutical Engineering College, Hubei University of Technology, \\ Wuhan, Hubei, China \\ ${ }^{2} \mathrm{C}$. Eugene Bennett Department of Chemistry, West Virginia University, Morgantown, WV, USA \\ ${ }^{3}$ Department of Chemistry, Johns Hopkins University, Baltimore, Maryland, USA \\ ${ }^{4}$ Department of Radiology, Johns Hopkins School of Medicine, Baltimore, Maryland, USA \\ Email: "hong.lai@jhu.edu
}

Received 14 May 2016; accepted 26 June 2016; published 29 June 2016

Copyright (C) 2016 by authors and Scientific Research Publishing Inc.

This work is licensed under the Creative Commons Attribution International License (CC BY).

http://creativecommons.org/licenses/by/4.0/

(c) (i) Open Access

\begin{abstract}
As a severe environmental pollutant, detection and quantitation of nitrogen dioxide $\left(\mathrm{NO}_{2}\right)$ have been studied for centuries. In this review, recent progress of $\mathrm{NO}_{2}$ analysis in the atmosphere will be summarized. Four major types of detection technologies, including traditional chemical detection, optical detection, solid-state field effect transistor detection, and other detection technology are covered. The standard method employed by the US EPA, which is based on luminol, is the most reliable and robust method that is used for fully validated monitoring. In the past two decades, accompanying the fast development of electrical engineering and integrated circuit, micro to nanoscale gas sensors have been gaining more and more attention. Application of novel materials including nano wires and graphene also leads to a new era of research and development of sensors.
\end{abstract}

\section{Keywords}

Nitrogen Dioxide, Chemical Detection, Optical Detection, Field-Effect Transistor Detection, Luminol

\section{Introduction}

\subsection{Background and Scope}

Nitrogen dioxide $\left(\mathrm{NO}_{2}\right)$ is one of the major environmental pollutants, which belongs to the family of nitrogen oxides $\left(\mathrm{NO}_{x}\right)$. The major source of $\mathrm{NO}_{2}$ in the air comes from combustion of fossil fuels [1]. $\mathrm{NO}_{2}$ gas forms

\footnotetext{
*These two authors contribute equally.

${ }^{\#}$ Corresponding author.
} 
when fuel is burned at high temperatures, primarily from the exhaust of motor vehicles and power plants. $\mathrm{NO}_{2}$ is a strong oxidizing agent that may form highly toxic nitric acid and organic nitrate. Furthermore, $\mathrm{NO}_{2}$ leads to the production of ground level ozone, which is also recognized as smog [2]. Studies have shown that $\mathrm{NO}_{2}$ and related derivatives $\left(\mathrm{NO}_{x}\right)$ will increase the risk of lung cancer [3] [4]. The International Agency for Research on Cancer recently classified outdoor air pollution and particulate matter as carcinogenic (Group 1) [5]. In the United States, EPA (Environmental Protection Agency) has set primary standards in compliant of the Clean Air Act of $\mathrm{NO}_{2}$ to not exceed $53 \mathrm{ppb}$ as annual mean (Figure 1) [6]. Therefore, fast, sensitive and reliable analysis of $\mathrm{NO}_{2}$ is an essential need for the public health, as well as for personal protection. In this review, we will summarize some of the key techniques reported to detect and quantitate $\mathrm{NO}_{2}$ in the past two decades, and give advice for further research.

\subsection{Types of Technology Used for $\mathrm{NO}_{2}$ Analysis}

Widely used $\mathrm{NO}_{2}$ analysis technologies can be divided into the following four categories based on the mechanism of detection: traditional chemical analysis, optical detection, field-effect transistor detection and other detection techniques.

\subsubsection{Traditional Chemical Analysis}

Analysis of $\mathrm{NO}_{2}$ and related substances such as $\mathrm{NH}_{3}$ and other nitrogen containing compounds can be dated to more than one hundred years ago [8]. These methods are often based on the chemical reactions of $\mathrm{NO}_{2}$ and/or other forms of nitrogen. $\mathrm{NO}_{2}$ are required to be converted to $\mathrm{NH}_{3}$ in certain detecting methods [8] [9]. Acid-base titration and reduction-oxidation titration was often used to determine the content of nitrogen species [8] [9]. Automated machineries were created to simplify this titration process and to enable the continuous analysis of large batches of samples [9]. However, the required sample size was large. Up to the order of several grams of sample was required for each analysis. Therefore, sensitivity was low as the limit of detection is $0.1 \%$ of the sample weight. Selectivity was also limited due to other interferences that also carry the same property [9].

\subsubsection{Optical Detection}

Luminol is achemical reagent that emits chemiluminescence in the presence of appropriate oxidizing agent and metal catalysts. $\mathrm{NO}_{2}$ is a strong oxidizer, which can readily trigger the chemiluminescence reaction of luminol. With the help of photon multiplier tube (PMT), detection of $\mathrm{NO}_{2}$ with luminal is very sensitive. Further

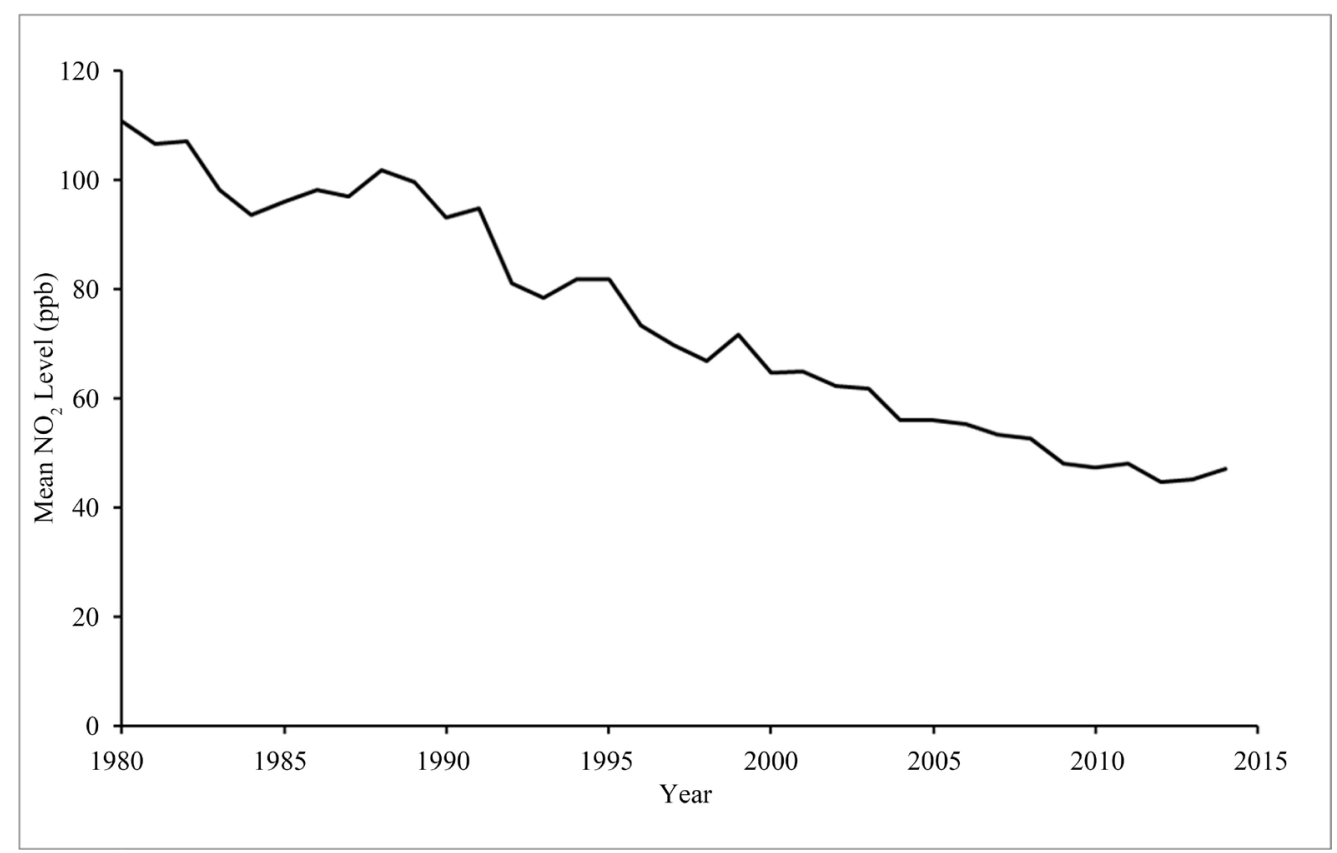

Figure 1. Mean $\mathrm{NO}_{2}$ level monitored across the US 1980-2014 [7]. 
developments of the chemiluminescence detection include utilizing luminol in a solid substrate support to simplify the design. It has become the standard analytical technique of $\mathrm{NO}_{2}$ in the quality evaluation of air. Cavity attenuated phase shift (CAPS) spectroscopy takes advantage of the phase shift caused by light signal in the presence of $\mathrm{NO}_{2}$ in an optical resonant cavity. Most interference can be filtered out by the highly selective and specific absorption of $\mathrm{NO}_{2}$, without compromising the high sensitivity achieved by PMT.

\subsubsection{Field-Effect Transistor Detection}

Absorption of $\mathrm{NO}_{2}$ or other gases may lead to changes of the chemical composition of a thin film of sensitive material. Electro-chemical behaviors including impedance, conductivity and resistivity will be changed accordingly. Therefore, detection and analysis of electrical signals can be used to calculate $\mathrm{NO}_{2}$ concentrations. With the help of signal detection and amplification by the rapidly developing field-effect transistor (FET) and integrated circuit (IC), many gas sensors were created and investigated [10]. These sensors can be made solid-state, versatile to use and economic to manufacture with fast response and small scale,

\subsubsection{Other Detection Techniques}

There are some other detection technologies for $\mathrm{NO}_{2}$ detection and quantitation. $\mathrm{NO}_{2}$ may lead to unique changes of physical or chemical properties of these materials that absorb $\mathrm{NO}_{2}$. One example is the change of frequencies of a piezoelectric crystal [11]. Another method is widely used in biological samples. $\mathrm{NO}_{2}$ reacts with tyrosyl radical to form nitrotyrosine, which is a biomarker of oxidative stress in patients with cardiovascular and neurodegenerative diseases. Immunoassay of this biomarker is capable to detect trace amount of $\mathrm{NO}_{2}$ reacting with myoglobin [12].

\section{Review of Technologies}

\subsection{Traditional Chemical Analysis}

Analysis of nitrogen content in organic samples started in the late $19^{\text {th }}$ century. Kjeldahl [8] published the work on digesting organic matters with sulfuric and phosphoric acids in 1888. The nitrogen content was converted to ammonium sulfate and then to ammonia, which was distilled into a measured volume of standard acid. Further analysis by acid-base titration of ammonia completed this indirect analysis of any form of nitrogen contents in the sample. Many researchers have worked on optimization of the classic Kjeldahl method to improve its digestion efficiency, while the essence of chemistry behind this method stays the same. This method has its own drawbacks on speed, accuracy, and most importantly, specificity. Almost all forms of nitrogen, including $\mathrm{NO}_{2}$, $\mathrm{NH}_{3}$, and other organic nitrogen, are analyzed as combined together.

Andres Ferrari proposed a system for continuous digestion and analysis based on the Kjeldahl method [9]. Automation of sample handling was performed with a grooved quartz tube, which was rotated by motor-driven wheels and allowed the sample solution to flow from one end of the tube to the other. The tube was heated inside a tube furnace to $400^{\circ} \mathrm{C}-600^{\circ} \mathrm{C}$. The high temperature and presence of oxidants converted nitrogen content into ammonium salts. The salts were then treated with excess of base. Afterwards, the liberated ammonia was collected in measured volume of standard acid. The residual acid was titrated with standard base, which quantified the total nitrogen content [9].

This automated method has produced similar results as the classic manual method with significantly reduced workload requirement. The rate of analysis using this automated system is up to 10 samples per hour. However, the classic methods are only capable of determining nitrogen content in single digit percentage. Limit of detection of both manual and automatic titration is about $0.1 \%$ of the sample weight.

\subsection{Optical Detection}

Chemiluminescence was the most prevalent and dominating method for the analysis of $\mathrm{NO}_{2}$ in the air. The United States Environmental Protection Agency (EPA) has published the official guidance of the standard chemiluminescence method for $\mathrm{NO}_{2}$ analysis [10]. This technique was first discussed in detail by Fontijn et al. in 1964 [13]. Since then, it has been intensively studied since then. The resulted reliable, simple and accurate method was then recommended by EPA and other regulatory agencies around the world as the first choice for routine $\mathrm{NO}_{2}$ analysis. 
The standard method regulated by EPA employs the creation of chemiluminescence using ozone. In this reaction, $\mathrm{NO}_{2}$ is first reduced to nitric oxide (NO). Then $\mathrm{NO}$ reacts with $\mathrm{O}_{3}$ to form the exited state of nitrogen dioxide, $\mathrm{NO}_{2}^{*}$, which emits light while returning back to the ground state of $\mathrm{NO}_{2}$.

$$
\begin{gathered}
\mathrm{NO}+\mathrm{O}_{3} \rightarrow \mathrm{NO}_{2}^{*}+\mathrm{O}_{2} \\
\mathrm{NO}_{2}^{*} \rightarrow \mathrm{NO}_{2}+h v .
\end{gathered}
$$

Intensity of light is proportional to the concentration of $\mathrm{NO}_{2}$. Commercially available instruments deliver a fully validated analysis and conform to EPA specifications. The dynamic range used for daily $\mathrm{NO}_{2}$ monitoring is from 0 to $500 \mathrm{ppb}$. Traceable $\mathrm{NO}$ or $\mathrm{NO}_{2}$ standards are also readily available for the calibration of the instruments. Instrument using the luminol method is currently the first and only method available in pursue of the regulated environmental monitoring of $\mathrm{NO}_{2}$ in air. $\mathrm{NO}$ and other nitrogen oxides are common interferences for this method. In addition, free radicals in the air may also reduce the amount of exited $\mathrm{NO}_{2}$, leading to a lower result.

Wendel described a continuous $\mathrm{NO}_{2}$ monitoring system capable of detecting $\mathrm{NO}_{2}$ in the sub ppb range [14]. This instrument employed several pumps to circulate air and the reagent solutions. PMT was used to detect the emitting light. Due to very high amplification gains of PMT, the detection limit is down to 30 pptr. Interference of $\mathrm{O}_{3}$ was avoided using gas washing prior to entering the reaction chamber. However, there were still interferences including other nitrogen oxides $\left(\mathrm{NO}_{x}\right)$. An alternative method is recommended for extreme cases in cluding field study, instead of using chemiluminescence. Collins et al. [15] [16] introduced an improved Luminol-based $\mathrm{NO}_{2}$ analysis (Figure 2). The solution circulation system was replaced by a thin film of hydrogel, which immobilized luminol with necessary catalysts.

Besides chemiluminescence, Cavity Attenuated Phase Shift Spectroscopy (CAPS) developed by Aerodyne Inc. was also used for $\mathrm{NO}_{2}$ analysis (Figure 3) [17] [18] [22]. CAPS is related to cavity ring-down spectroscopy (CRDS). In CAPS and CRDS, the measurements of light absorption are made possible by using an extremely long effective path length. A beam of laser is introduced into a cavity with two highly reflective mirrors. The light can "bounce" back and forth with path length over one kilometer. The resulting signal measured at the exit mirror will show exponential decay over time (Ring-down). The decay time is related to the concentration of the<smiles>Nc1cccc(C(=O)O)c1C(=O)O</smiles>

Figure 2. Basic chemiluminescence reactions between luminol and $\mathrm{NO}_{2}[16]$.

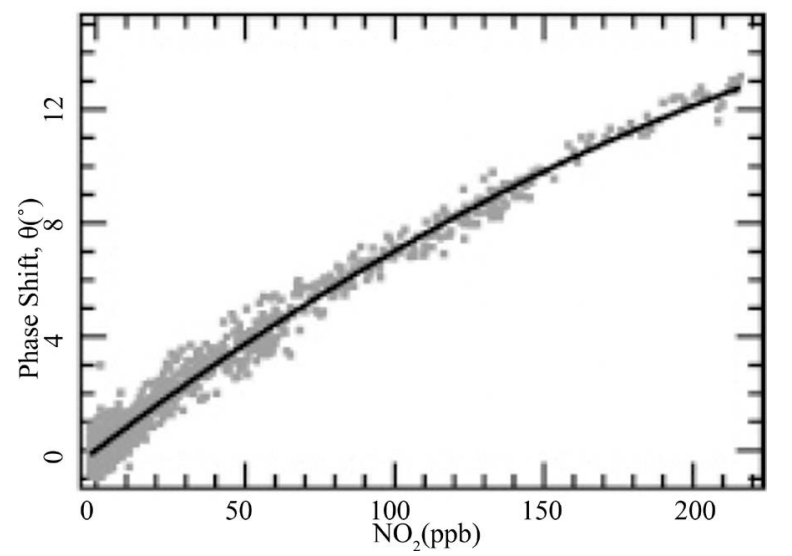

Figure 3. Calibration of CAPS $\mathrm{NO}_{2}$ sensor [22] (re-printed with permission). 
light-absorbing species in the cavity [23] [24].

The main oscillation chamber used in CAPS was constructed using two highly reflective mirrors facing each other, similar to CRDS. A beam of modulated broadband light created by LED is directed into the chamber. Presence of $\mathrm{NO}_{2}$ causes a phase shift in the signal output, which is proportional to the concentration of $\mathrm{NO}_{2} .430$ $\mathrm{nm}$ was chosen as the light wavelength because it matches the maximum absorption of $\mathrm{NO}_{2}$. With the use of an interference filter, the limit of detection is $0.5 \mathrm{ppb}$. This sensor is capable of measuring $0-200 \mathrm{ppb}$ of $\mathrm{NO}_{2}$ in the air. However, the noticeable curvature seen in the calibration towards $200 \mathrm{ppb}$ is caused by loss of light during absorption, which is comparable to the phase shift effect at higher concentrations [22]. Table 1 summarized chemiluminescence and non-chemiluminescence techniques used in optical $\mathrm{NO}_{2}$ detection.

\subsection{Field Effect Transistor Detection}

Though chemical and optical analysis techniques are good options for $\mathrm{NO}_{2}$ analysis, researchers are continuously seeking for new sensors that are in solid state, easy to operate, maintenance-free and small in size. Without the requirement of any chemical solutions, gas sensors have been made perfect candidates for varies of applications both in the lab and the field. Its simplicity also enables the mass production with relatively low cost for each unit. Integration with modern electrical engineering allows direct control and digital signal transmission to a data collection device. Interest for the FET gas sensors is increasing, accompanying hundreds of research articles and communication papers in this field. The study of sensor design and material has been divided into two ways. One is the optimization of the sensing performance. The other is the additional feature and utilizations on top of the good performance.

Early work on FET gas sensors can be tracked back to 1980s. In a study by Kolesar et al. [25] in 1989, IGEFET was coupled to a thin film of copper phthalocyanine (CuPc), which selectively reacted with IGE-FET at ppb levels. Measurement was based on the sensitivity of the field effect transistor's output current to changes in the molecular structure or chemical composition of the thin film which covers the interdigitated gate electrode.

A versatile sensor platform of $\mathrm{NO}_{2}$ in the air was developed by Oprea et al. in 2007 (Figure 4) [26]. This

Table 1. Comparison of optical $\mathrm{NO}_{2}$ detection technologies.

\begin{tabular}{|c|c|c|c|c|}
\hline & Technology & $\begin{array}{l}\text { Limit of } \\
\text { detection }\end{array}$ & Typical range & Reference/Note \\
\hline \multirow{3}{*}{ Chemiluminescence } & $\begin{array}{l}\mathrm{NO}_{2} \text { detector based on reaction } \\
\text { between Luminol and } \mathrm{NO}_{2} \text { in air }\end{array}$ & $10 \mathrm{ppt}$ & 65ppt - 18 ppb & Fast response $\sim 1$ s [14] \\
\hline & $\begin{array}{l}\text { Poly-gel Immobilized Luminol } \\
\mathrm{NO}_{2} \text { sensor }\end{array}$ & $460 \mathrm{ppt}$ & $0.5-20 \mathrm{ppb}$ & $\begin{array}{l}\text { The gel substrate needs to be } \\
\text { replaced every day [15]. }\end{array}$ \\
\hline & US EPA standard $\mathrm{NO}_{2}$ test method & $\sim 1 \mathrm{ppb}$ & $1-500$ ppb & $\begin{array}{l}\text { LOD and range will vary slightly } \\
\text { on different conditions [10]. }\end{array}$ \\
\hline \multirow{4}{*}{ Non- Chemiluminescence } & $\begin{array}{l}\text { Cavity Attenuated Phase Shift } \\
\text { (CAPS) } \mathrm{NO}_{2} \text { detector }\end{array}$ & $0.3 \mathrm{ppb}$ & $0.5-200 \mathrm{ppb}$ & $\begin{array}{l}\text { Very fast response, suitable for } \\
\text { online monitoring [17] [18] }\end{array}$ \\
\hline & $\begin{array}{l}\text { CAPS } \mathrm{NO}_{2} \text { detector, second } \\
\text { generation }\end{array}$ & $0.06 \mathrm{ppb}$ & $0-320$ ppb & $\begin{array}{l}\text { Improved accuracy and sensitivity } \\
\text { [19] }\end{array}$ \\
\hline & Miniature fiber-optic spectroscopy & $\sim 10 \mathrm{ppb}$ & $15-50 \mathrm{ppb}$ & $\begin{array}{l}\text { Semi quantitative with a relatively } \\
\text { large error }( \pm 20 \%)[20]\end{array}$ \\
\hline & DPPD-polymer $\mathrm{NO}_{2}$ detector & $0.12 \mathrm{ppm}$ & $0.1-25 \mathrm{ppm}$ & Small scale integrated sensor [21] \\
\hline
\end{tabular}

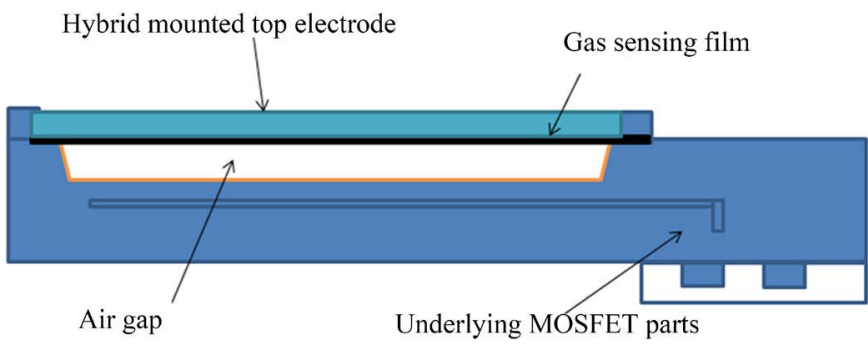

Figure 4. Schematic cross-section of a suspended gate gas sensor [26]. 
platform was based on capacitive coupled field effect transistors (CC-FET). Unlike other common gas sensors, the sensing material in this study was suspended on top of the substrate, which is called suspended gates (SG) [26]. There is a small gap of $1-5 \mu \mathrm{m}$ distance between SG and the FET channel. A schematic illustration is shown in Figure 4. Therefore, the sensing material can be separated from the platform so that a large variety of materials and substrates can be tested. Sensing thin film can be easily replaced and compared in parallel under exactly the same testing conditions.

In the past two decades, a great deal of research work has been focused on resistance and conductivity gas sensors [10] [25] [27]-[32]. In this type of sensors, a thin film usually made of semiconductor oxide serves as the main sensing material. Concentration of $\mathrm{NO}_{2}$ is directly related to resistance and conductivity of the material and is measurable with peripheral circuits. The center of many current research targets at discovering and developing better sensing materials.

$\mathrm{NO}_{2}$ is an oxidizing gas so it induces an increase of resistance and impedance of n-type semiconductors. Sensors based on semiconducting metal oxides have been developed and reviewed by a number of researchers [29]. The base material includes tin oxide $\left(\mathrm{SnO}_{2}\right)$, tungsten oxide $\left(\mathrm{WO}_{3}\right)$, indium oxide $\left(\mathrm{In}_{2} \mathrm{O}_{3}\right)$, titanium oxide $(\mathrm{TiO})_{2}$, zinc oxide ( $\mathrm{ZnO}$ ) and other non-metal materials such as polymers and grapheme [28]-[30] [33]-[35]. In addition, doping and use of different additive materials has opened another pathway of developing new sensing materials. Common preparation methods are chemical vapor deposition (CVD), electrophoretic deposition, electrostatic spray, solution precursor plasma-spray and other similar approach. Characterization of the microscopic structure of these materials usually utilizes technologies such as X-ray powder diffraction (XRD), scanning electron microscope (SEM), Transmission electron microscopy (TEM), atomic force microscope (AFM) and X-ray photoelectron spectroscopy (XPS).

$\mathrm{ZnO}$ has been proved to be a stable, low cost and non-toxic sensing material. However, the sheet resistance of pure $\mathrm{ZnO}$ thin film is substantially high. If impedance of the sensor becomes higher, the resulting weak signal of current change will considerably increase the complexity of the associated controlling and measuring circuitry of instruments, though sensing of $\mathrm{NO}_{2}$ is based on the increase of resistance. Data may also become distorted at such week signal levels. Ferro et al. [28] reported indium and cadmium doped ZnO thin films with a lowered resistance and improved performance. Spray pyrolysis was used for its simplicity, low cost and ability for mass production. Undoped $\mathrm{ZnO}$ sensor was tested with different film thickness and grain size in order to find an optimized combination. The best amount of doping was 3\% w/w. Fast response and recovery was observed at an operating temperature of $275^{\circ} \mathrm{C}$. The effect of gas sensing with the additive was considered not related to electronic catalytic mechanism because increased carrier concentrations by doping deteriorate performance of the sensor. The reaction mechanism was proved to be the increase of the surface active area and the number of active absorbing sites, by using SEM and AFM to examine the surface structure of the doped sensing film. The detectable range of doped $\mathrm{ZnO}$ film is 0 - 5 ppm [28].

In addition, sensors of oxidizing gases usually utilize high temperature to enhance the desorption kinetics. In studies of gas sensors, response time (T90) is defined as the time required for the signal to reach $90 \%$ of the final value upon exposure of the target gas, while the recovery time (T10) is the time for the signal to reduce to $10 \%$ of the highest level when the target gas is removed. Slow response and recovery within 10 - 60 min is commonly observed across this type of sensors (Figure 5) [30]. Several types of sensors that may function at room temperature have been discovered and investigated. However, the lowered temperature may slow down the response and recovery further more. A reported $\mathrm{In}_{2} \mathrm{O}_{3}$ nanowire sensor showed a response to sub-ppm level $\mathrm{NO}_{2}$ in 15 min with a recovery time of 45 - $90 \mathrm{~min}$. [31] Another study by Liu et al. [29] significantly lowered the requirement of high operating temperature, which is usually $300^{\circ} \mathrm{C}-500^{\circ} \mathrm{C}$ and observed among resistive gas sensors. Kinetic studies have shown that absorption of $\mathrm{NO}_{2}$ on the surface of sensing materials was much faster than the desorption process.

Graphene has recently been reported as a potent material for construction of sensors, small-scale electronics and solar cells. The unique wide-spread 2D structure of graphene reassembles a honeycomb lattice, which forms $\pi$ bonds across the hexagonal skeleton. $\pi$ bondis half filled and allows free-flowing electrons, which contributes to the most notable electronic properties of graphene, the quantum Hall effect [36] [37]. The selective absorption and desorption was demonstrated by Ko et al. [32]. Unlike other metal oxide thin film gas sensors, adsorption of $\mathrm{NO}_{2}$ molecule increases of conductivity of graphene sensors. As Zhang et al. suggested there were three possible configurations of the adsorption, the nitro-, nitrite- and cyclo-addition, increase of conductivity of graphene is due to charge transfer between $\mathrm{NO}_{2}$ molecules and graphene. Desorption has been found to be a very slow 
process. A possible way to expedite it is to expose the sensor under UV radiation [32].

When reduced graphene oxide is sprayed withasoluble semiconducting polymer, a double-layered sensing film is formed. Xie et al. [33] reported that the use of poly-(3-hexylthiophene) (P3HT), which is a p type semiconducting polymer, can enhance the gas sensing properties (Figure 6). The double-layered material was constructed on an existing organic thin film transistor (OTFT) sensor platform. Pure P3HT thin film was prepared and compared to the double layer of P3HT/Graphene designs. P3HT and/or Graphene layers were applied to the OTFT substrate using an air brushing technique.

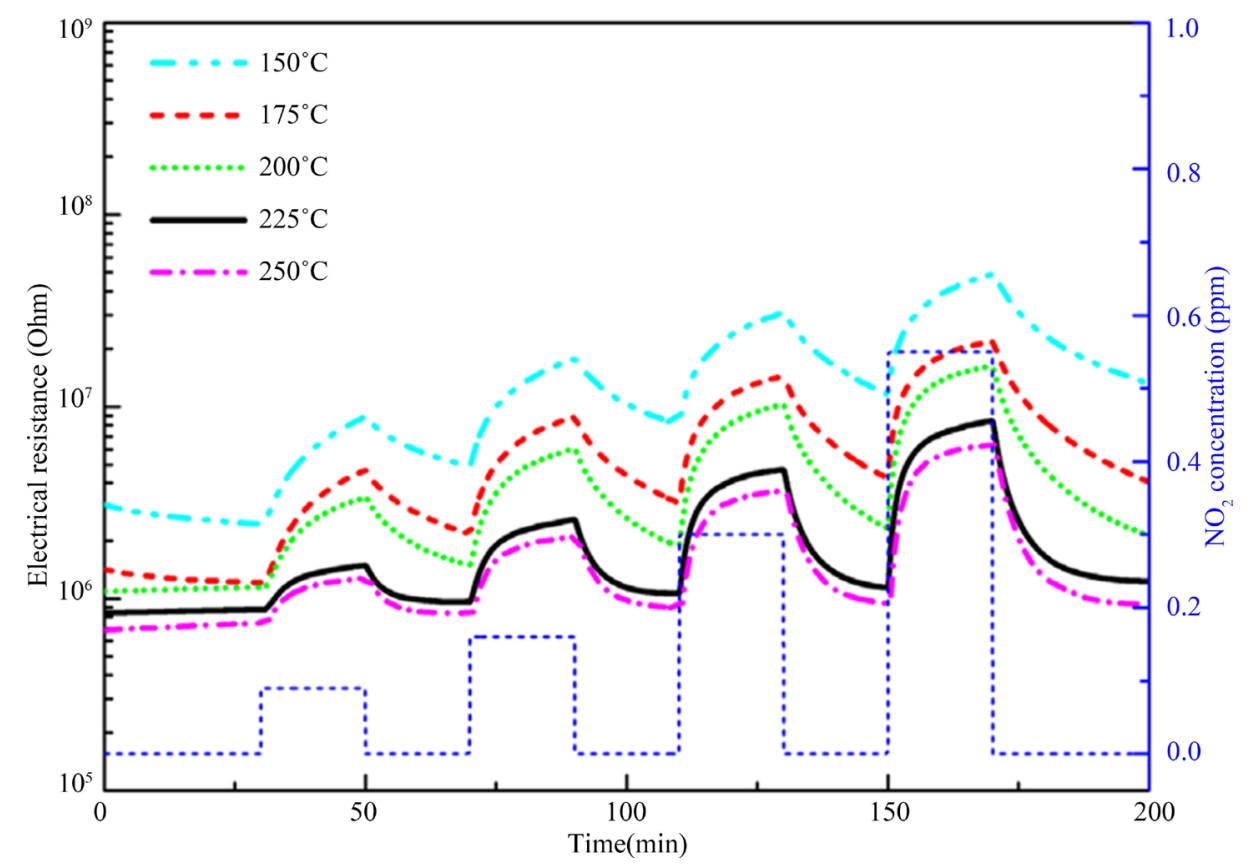

Figure 5. Typical resistance sensor response of $\mathrm{NO}_{2}$ at different temperature [30] (Re-printed with permission).

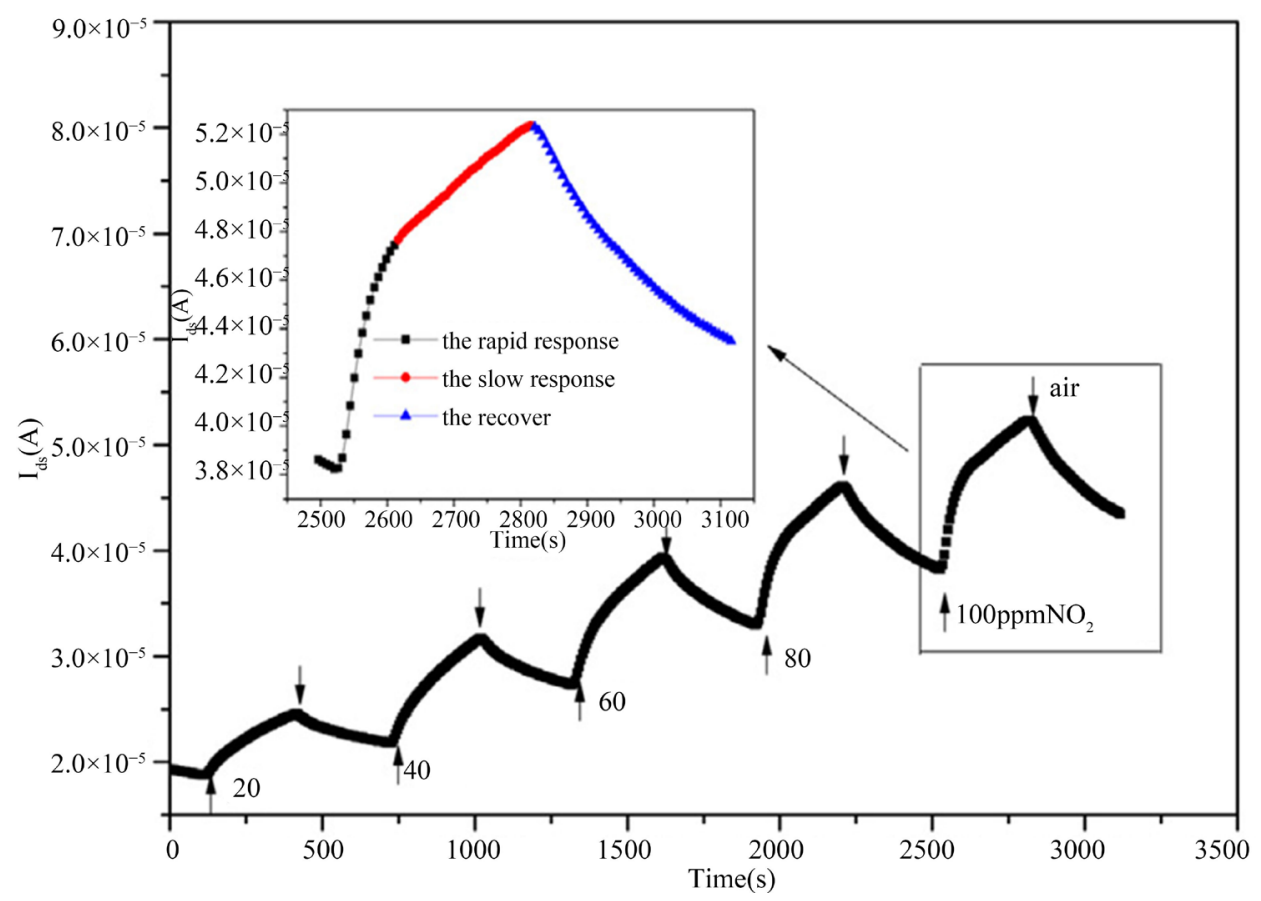

Figure 6. Response of graphene/P3HT double layer gas sensing material [33] (re-printed with permission). 
Table 2. Comparison of major detection categories.

\begin{tabular}{cll}
\hline Type & \multicolumn{1}{c}{ Pros } & \multicolumn{1}{c}{ Cons } \\
\hline Chemical & $\begin{array}{l}\text { Simple processing without the need of expensive } \\
\text { equipment/instrument }\end{array}$ & $\begin{array}{l}\text { Poor sensitivity; Requires the use of chemicals; Low throughput } \\
\text { and high labor demand }\end{array}$ \\
Optical & $\begin{array}{l}\text { Highly reliable and fully validated detection with the use } \\
\text { of luminal; Very high sensitivity with CAPS detector }\end{array}$ & $\begin{array}{l}\text { High cost of instrument purchase and maintenance; Unable to } \\
\text { use in small scale sensors }\end{array}$ \\
FET & $\begin{array}{l}\text { Solid state sensors without chemicals; Continuously } \\
\text { monitoring (on-line analysis) }\end{array}$ & $\begin{array}{l}\text { The accuracy and reliability can still be improved by } \\
\text { developing new sensing materials }\end{array}$ \\
\hline
\end{tabular}

The response to exposure of $\mathrm{NO}_{2}$ showed a very interesting three-stage curve, the rapid response, the slow response and the recovery, especially at higher concentrations of $\mathrm{NO}_{2}$. The mechanism that caused the 3 stages can be explained that at higher concentrations (over $60 \mathrm{ppm}$ ), the rapid rise of signal (stage 1) is due to the adsorption of gas molecules onto low energy bonding sites such as sp2-bonded carbon. With gradual saturation of these sites, the gas molecules will interact with higher energy sites such as vacancies and structural defects, which is much slower (stage 2). Stage 3 showed an exponential decay of the signal when the analyte $\left(\mathrm{NO}_{2}\right)$ was purged out with air. However, at lower $\mathrm{NO}_{2}$ concentrations, only very few $\mathrm{NO}_{2}$ molecules can reach to the surface of graphene through the P3HT top layer. The fast responding low energy sites will not be saturated. Thus all the $\mathrm{NO}_{2}$ molecules interact with the low energy sites, which lead to a relatively fast over-all response.

One of the major drawbacks of graphene based sensing material is the baseline shift. As showed also in the response curve over time, the recovery of the signal did not go back to the original level, especially after exposure to high levels of $\mathrm{NO}_{2}$. Within $90 \mathrm{~min}$, the signal will return to baseline close to the original value, but long recovery is not desirable in practice and needs further investigation for improvement.

\subsection{Other Detection Technologies}

Besides these dominating detection techniques mentioned above, there are other methods to analyze $\mathrm{NO}_{2}$, such as Gas Chromatography/Mass Spectrometry (GC/MS), Residual Gas Analyzer (RGA) and immunochemical methods [38]-[40]. One example is the detection of $\mathrm{NO}_{2}$ using piezoelectric quartz crystal [11].Vibration frequency of an oscillating crystal may be decreased by substances that are absorbed on the surface of crystal. Selectivity is achieved by carefully choosing a coating material on the surface of the piezoelectric crystals. In the study by Karmarkar et al., two types of materials, Ucon 75-H-90000 and Ucon-LB-300X were chosen for the specified detection of $\mathrm{NO}_{2}$ and $\mathrm{NH}_{4}$, respectively [11]. Base frequency of the crystal was $9 \mathrm{MHz}$. A $40 \mathrm{~Hz}$ decrease was observed with exposure to about $1 \mathrm{ppm}$ of $\mathrm{NO}_{2}$ in the sample mixture. The response as change of frequency was linear in the range from $1 \mathrm{ppb}$ to $1 \mathrm{ppm}$. The response time was about 5 minutes. In short, the piezoelectric crystal is a good detector with high sensitivity, without use of liquid chemicals or moving parts. However, there are drawbacks of this type of detector. First, it responses to atmospheric moisture. It would be difficult to distinguish between the effect of moisture and a true air pollutant. A dry wash device can be used to eliminate moisture content, before the air samples enter the detector. Another drawback is that after a long exposure to air, the detector loses all the detection ability to $\mathrm{NO}_{2}$. This disability may be reversed by exposing the detector to $\mathrm{NO}_{2}$ mixture again for a short time [11].

\section{Summary}

A brief review of $\mathrm{NO}_{2}$ analysis technologies has been presented in this paper. The advantages and disadvantages of the categories are compared in Table 2.

The research of $\mathrm{NO}_{2}$ detection has gone a long way from the first discovery of chemiluminescence with Luminol. The reviewed technologies were classified into categories by the sensing properties. Selected important studies that represent the key characteristics are included. Factors that affect the sensing characters are analyzed. Trends of improvements are also discussed. The current active studies of $\mathrm{NO}_{2}$ analysis focus on two major paths. One is the environmental analysis regulated by the EPA or other governments, which is also known as the regulatory measurements. Another more cutting edge area of study is the development of gas sensing material, especially semi-conductive thin films. These materials have great potential of applications on versatile, solid state, small scale and maintenance-free devices. 


\section{References}

[1] Shi, Y., Xia, Y., Lu, B., Liu, N., Zhang, L., Li, S. and Li, W. (2014) Emission Inventory and Trends of $\mathrm{NO}_{x}$ for China, 2000-2020. Journal of Zhejiang University SCIENCE A, 15, 454-464. http://dx.doi.org/10.1631/jzus.A1300379

[2] Wilkins, C., Clausen, P., Wolkoff, P., Larsen, S., Hammer, M., Larsen, K., Hansen, V. and Nielsen, G. (2001) Formation of Strong Airway Irritants in Mixtures of Isoprene/Ozone and Isoprene/Ozone/Nitrogen Dioxide. Environ Health Perspect, 109, 937-941. http://dx.doi.org/10.1289/ehp.01109937

[3] Hamra, G., Laden, F., Cohen, A., Raaschou-Nielsen, O., Brauer, M. and Loomis, D. (2015) Lung Cancer and Exposure to Nitrogen Dioxide and Traffic: A Systematic Review and Meta-Analysis. Environ Health Perspect, 123, 111. http://dx.doi.org/10.1289/ehp.1408882

[4] Rohde, R. and Muller, R. (2015) Air Pollution in China: Mapping of Concentrations and Sources. PLoS ONE, 10, e0135749. http://dx.doi.org/10.1371/journal.pone.0135749

[5] International Agency for Research on Cancer (IARC) (2013) Outdoor Air Pollution a Leading Environmental Cause of Cancer Deaths. World Health Org. Press Release No. 221.

[6] National Ambient Air Quality Standards (1971) US Code of Federal Regulations. 36 FR 8186 Apr. 30.

[7] (2014) National Trends in Nitrogen Dioxide Levels 1980-2014. US EPA Publication, Washington DC.

[8] Kjeldahj, J. (1883) Neue Methodezur Bestimmung des Stickstoffs in organischen Körpern. Zeitschrift für Analytische Chemie, 1, 366-383.

[9] Ferrari, A. (1960) Nitrogen Determination by a Continuous Digestion and Analysis System. Annals of the New York Academy of Sciences, 87, 792-800. http://dx.doi.org/10.1111/j.1749-6632.1960.tb23236.x

[10] US EPA Quality Assurance Guidance Document 2.3 Reference (2002) Method for the Determination of Nitrogen Dioxide in the Atmosphere.

[11] Karmarkar, K. and Guilbault, G. (1975) The Detection of Ammonia and Nitrogen Dioxide at the Parts per Billion Level with Coated Piezoelectric Crystal Detectors. Analytica Chimica Acta, 75, 111-117. http://dx.doi.org/10.1016/S0003-2670(01)81958-9

[12] Nakai, K. and Mason, R.P. (2005) Immunochemical Detection of Nitric Oxide and Nitrogen Dioxide Trapping of the Tyrosyl Radical and the Resulting Nitrotyrosine in Sperm Whale Myoglobin. Free Radical Biology \& Medicine, 39, 1050-1058. http://dx.doi.org/10.1016/j.freeradbiomed.2005.05.019

[13] Fontijn, A., Meyer, C. and Schiff, H. (1964) Absolute Quantum Yield Measurements of the NO-O Reaction and Its Use as a Standard for Chemiluminescent Reactions. The Journal of Chemical Physics, 40, 64. http://dx.doi.org/10.1063/1.1724895

[14] Wendel, G., Stedman, D. and Cantrell, C. (1983) Luminol-Based Nitrogen Dioxide Detector. Analytical Chemistry, 55, 937-940. http://dx.doi.org/10.1021/ac00257a027

[15] Collins, G. and Rose-Pehrsson, S. (1995) Chemiluminescent Chemical Sensors for Oxygen and Nitrogen Dioxide. Analytical Chemistry, 67, 2224-2230. http://dx.doi.org/10.1021/ac00109a049

[16] Huntress, E., Stanley, L. and Parker, A. (1934) The Preparation of 3-Aminophthalhydrazide for Use in the Demonstration of Chemiluminescence. Journal of the American Chemical Society, 56, 241-242. http://dx.doi.org/10.1021/ja01316a077

[17] Kebabian, P., Wood, E., Herndon, S. and Freedman, A. (2005) Detection of Nitrogen Dioxide by Cavity Attenuated Phase Shift Spectroscopy. Analytical Chemistry, 77, 724-728.

[18] Weeksrtom, K. (2004) US Patent No. 6791689 B1.

[19] Kebabian, P., Wood, E., Herndon, S. and Freedman, A. (2008) A Practical Alternative to Chemiluminescence-Based Detection of Nitrogen Dioxide: Cavity Attenuated Phase Shift Spectroscopy. Environmental Science \& Technology, 42, 6040-6045. http://dx.doi.org/10.1021/es703204j

[20] Morales, J. and Walsh, J. (2005) Detection of Atmospheric Nitrogen Dioxide Using a Miniaturised Fibre-Optic Spectroscopy System and the Ambient Sunlight. Spectrochimica Acta Part A, 61, 2073-2079. http://dx.doi.org/10.1016/j.saa.2004.08.007

[21] Alexy, M., Hanko, M., Rentmeister, S. and Heinze, J. (2006) Disposable Optochemical Sensor Chip for Nitrogen Dioxide Detection Based on Oxidation of $N, N^{\prime}$-Diphenyl-1,4-Phenylenediamine. Sensors and Actuators B, 114, 916-927. http://dx.doi.org/10.1016/j.snb.2005.08.041

[22] Kebabian, P., Herndon, S. and Freedman, A. (2005) Detection of Nitrogen Dioxide by Cavity Attenuated Phase Shift Spectroscopy. Analytical Chemistry, 77, 724-728. http://dx.doi.org/10.1021/ac048715y

[23] Wheeler, M.D. and Newman, S.M. (1998) Cavity Ring-Down Spectroscopy. Journal of the Chemical Society, Faraday 
Transactions, 94, 337-351. http://dx.doi.org/10.1039/a707686j

[24] Herbelin, J.M. and McKay, J.A. (1981) Development of Laser Mirrors of Very High Reflectivity Using the Cavity-Attenuated Phase-Shift Method. Applied Optics, 20, 3341-3344. http://dx.doi.org/10.1364/AO.20.003341

[25] Kolesar Jr., E. and Wiseman, J. (1989) Interdigitated Gate Electrode Field Effect Transistor for the Selective Detection of Nitrogen Dioxide and Diisopropyl Methylphosphonate. Analytical Chemistry, 61, 2355-2361. http://dx.doi.org/10.1021/ac00196a008

[26] Oprea, A., Frerichs, H., Wilbertz, C., Lehmann, M. and Weimar, U. (2007) Hybrid Gas Sensor Platform Based on Capacitive Coupled Field Effect Transistors: Ammonia and Nitrogen Dioxide Detection. Sensors and Actuators B, 127, 161-167. http://dx.doi.org/10.1016/j.snb.2007.07.030

[27] Eisele, I., Doll, T. and Burgmair, M. (2001) Low Power Gas Detection with FET Sensors. Sensors and Actuators B, 78, 19-25. http://dx.doi.org/10.1016/S0925-4005(01)00786-9

[28] Ferro, R., Rodríguez, J. and Bertrand, P. (2008) Peculiarities of Nitrogen Dioxide Detection with Sprayed Undoped and Indium-Doped Zinc Oxide Thin Films. Thin Solid Films, 516, 2225-2230. http://dx.doi.org/10.1016/j.tsf.2007.07.189

[29] Liu, H., Wan, J., Fu, Q., Li, M., Luo, W., Zheng, Z., Cao, H., Hu, Y. and Zhou, D. (2013) Tin Oxide Films for Nitrogen Dioxide Gas Detection at Low Temperatures. Sensors and Actuators B, 177, 460-466. http://dx.doi.org/10.1016/j.snb.2012.11.051

[30] Zhang, C., Genga, X., Olivier, M., Liao, H. and Debliquy, M. (2014) Solution Precursor Plasma-Sprayed Tungsten Oxide Coatings for Nitrogen Dioxide Detection. Ceramics International, 40, 11427-11431. http://dx.doi.org/10.1016/j.ceramint.2014.03.109

[31] Surwade, S., Agnihotra, S., Dua, V. and Manohar, S. (2009) Nitrogen Dioxide Vapor Detection Using Poly-oToluidine. Sensors and Actuators B, 143, 454-457. http://dx.doi.org/10.1016/j.snb.2009.09.033

[32] Ko, G., Kim, H.-Y., Ahn, J., Park, Y.-M., Lee, K.-Y. and Kim, J. (2010) Graphene-Based Nitrogen Dioxide Gas Sensors. Current Applied Physics, 10, 1002-1004. http://dx.doi.org/10.1016/j.cap.2009.12.024

[33] Xie, T., Xie, G., Zhou, Y., Huang, J., Wu, M., Jiang, Y. and Tai, H. (2014) Thin Film Transistors Gas Sensors Based on Reduced Graphene Oxide Poly(3-Hexylthiophene) Bilayer Film for Nitrogen Dioxide Detection. Chemical Physics Letters, 614, 275-281. http://dx.doi.org/10.1016/j.cplett.2014.09.028

[34] Choi, Y.J., Hwang, I.S., Park, J.G., Choi, K.J., Park, J.H. and Lee, J.H. (2008) Novel Fabrication of an $\mathrm{SnO}_{2} \mathrm{Nanowire}$ Gas Sensor with High Sensitivity. Nanotechnology, 19, Article ID: 095508. http://dx.doi.org/10.1088/0957-4484/19/9/095508

[35] Nalagea, S.R., Navalea, S.T., Manec, R.S., Naushadd, M, Stadlarb, F.J. and Patila, V.B. (2015) Preparation of Camphor-Sulfonic Acid Doped PPy-NiO Hybrid Nanocomposite for Detection of Toxic Nitrogen Dioxide. Synthetic Metals, 209, 426-433. http://dx.doi.org/10.1016/j.synthmet.2015.08.018

[36] Zhang, Y., Tan, Y., Stormer, H.L. and Kim, P. (2005) Experimental Observation of the Quantum Hall Effect and Berry’s Phase in Grapheme. Nature, 438, 201-204. http://dx.doi.org/10.1038/nature04235

[37] Geim, A.K. and Novoselov, K.S. (2007) The Rise of Grapheme. Nature Materials, 6, 183-191. http://dx.doi.org/10.1038/nmat1849

[38] King, W.H. (1974) Piezoelectric Sorption Detector. Analytical Chemistry, 36, 1735-1739. http://dx.doi.org/10.1021/ac60215a012

[39] Finklea, H.O., Zhang, W., Jony, M. and Demirgok, B. (2015) Mass Spectrometry of SOFC Fuel Mixtures Containing Phosphine. Journal of the Electrochemical Society, 162, F1101-F1105. http://dx.doi.org/10.1149/2.1051509jes

[40] Reston, R.R. and Kolesar, E. (1994) Silicon-Micromachined Gas Chromatography System Used to Separate and Detect Ammonia and Nitrogen Dioxide. I. Design, Fabrication, and Integration of the Gas Chromatography System. Journal of Microelectromechanical Systems, 3, 134-146. http://dx.doi.org/10.1109/84.338634 


\section{Abbreviation List}

$\mathrm{NO}_{2}$ : nitrogen dioxide

US: United States of America

EPA: Environmental Protection Agency

$\mathrm{NH}_{3}$ : ammonia

PMT: photon multiplier tube

CAPS: cavity attenuated phase shift

FET: field-effect transistor

IC: integrated circuit

NO: nitric oxide

$\mathrm{O}_{3}$ : ozone

$\mathrm{NO}_{2}^{*}$ : exited state of nitrogen dioxide

$\mathrm{NO}_{x}$ : nitrogen oxides

CRDS: cavity ring-down spectroscopy

IGE-FET: interdigitated gate electrode field-effect transistor

CuPc: copper phthalocyanine

CC-FET: capacitive coupled field effect transistors

SG: suspended gates

$\mathrm{SnO}_{2}$ : tin oxide

$\mathrm{WO}_{3}$ : tungsten oxide

$\mathrm{In}_{2} \mathrm{O}_{3}$ : indium oxide

$\mathrm{TiO}_{2}$ : titanium oxide

ZnO: zinc oxide

CVD: chemical vapor deposition

XRD: X-ray powder diffraction

SEM: scanning electron microscope

TEM: Transmission electron microscopy

AFM: atomic force microscope

XPS: X-ray photoelectron spectroscopy

P3HT: poly-(3-hexylthiophene

OTFT: organic thin film transistor

Submit or recommend next manuscript to SCIRP and we will provide best service for you:

Accepting pre-submission inquiries through Email, Facebook, Linkedin, Twitter, etc A wide selection of journals (inclusive of 9 subjects, more than 200 journals)

Providing a 24-hour high-quality service

User-friendly online submission system

Fair and swift peer-review system

Efficient typesetting and proofreading procedure

Display of the result of downloads and visits, as well as the number of cited articles

Maximum dissemination of your research work

Submit your manuscript at: http://papersubmission.scirp.org/ 